\title{
Formal Insertion of Thioketenes into Donor-Acceptor Cyclopropanes by Lewis Acid Catalysis
}

\author{
André U. Augustin, ${ }^{\dagger}$ Marius Busse ${ }^{\dagger}$ Peter G. Jones,${ }^{\dagger}$ Daniel B. Werz ${ }^{\dagger}, *$ \\ 'Institute for Organic Chemistry and ${ }^{+}$Institute for Inorganic and Analytical Chemistry, TU Braunschweig, Hagenring 30, \\ 38106 Braunschweig, Germany
}

Supporting Information Placeholder

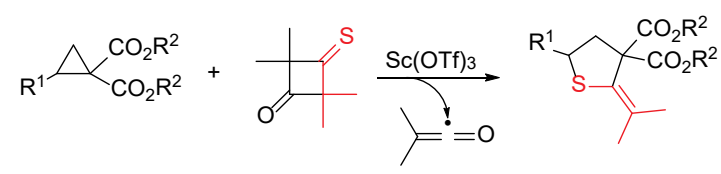

\begin{abstract}
Donor-acceptor cyclopropanes were reacted under Lewis acid catalysis with 3-thioxocyclobutanones as surrogates for disubstituted thioketenes. A broad scope of 2-substituted tetrahydrothiophenes with a semicyclic double bond was obtained under mild conditions, with high functional group tolerance and in excellent yield. A sequence of a formal [3+2]-cycloaddition followed by a subsequent release of disubstituted ketene is postulated as the mechanism.
\end{abstract}

In the recent past donor-acceptor (D-A) cyclopropanes have become a center of attention in organic synthesis as valuable three-membered building blocks. Even though the pioneering work by Wenkert and Reissig took place in the 1970s and $1980 \mathrm{~s},{ }^{1}$ only in the last decade they have been extensively utilized by many groups to access complex carbo- and heterocyclic scaffolds and have even been employed in natural product synthesis. $^{2}$ The vicinal arrangement of donor and acceptor substituents in combination with a high ring strain of about 115 $\mathrm{kJ} / \mathrm{mol}$ explains why they commonly react with 1,3-zwitterionic character, ${ }^{3}$ and this special behavior paves the way for numerous transformations. Whereas cycloaddition processes ${ }^{4}$ have been the most popular, rearrangements ${ }^{5}$ and ring-opening reactions ${ }^{6}$ by either nucleophiles, electrophiles or radicals have also been investigated.

Within the broad variability of possible reactions, Stoltz and coworkers reported a Lewis acid-mediated [3+2]-cycloaddition of D-A cyclopropanes with heterocumulenes under mild conditions. Isocyanates, isothiocyanates and carbodiimides undergo efficient insertion in a chemoselective manner to form the respective five-membered heterocycles (Scheme 1a). ${ }^{7}$ Very recently, Yang extended this method to the insertion into $\gamma$-butyrolactone-fused cyclopropanes to obtain single stereoisomers of the corresponding thioimidates and amidines, ${ }^{8}$ whereas Wang showed an elegant intramolecular cross-cycloaddition of allenes linked to cyclopropane 1,1-diesters to afford [4.3.0]bicyclononane and [3.2.1] bicyclooctane scaffolds. ${ }^{9}$

Based upon these results, we were keen to test whether a formal thioketene insertion into D-A cyclopropanes is able to deliver similar sulfur analogs (Scheme 1b). Because thioketenes are rather unstable and only a few examples have been reported, ${ }^{10}$ we turned our attention to 3-thioxocyclobutanones as suitable surrogates for disubstituted thioketene moieties. From our recent studies we know that thioketones can be inserted into the polarized three-membered ring systems. ${ }^{11}$ Thus, we proposed that tetrahydrothiophene scaffolds with a semicyclic double bond should arise from an analogous process with D-A cyclopropanes via a formal [3+2]-cycloaddition followed by a [2+2]-cycloreversion, releasing disubstituted ketene.

\section{Scheme 1. $[3+2]-C y c l o a d d i t i o n$}

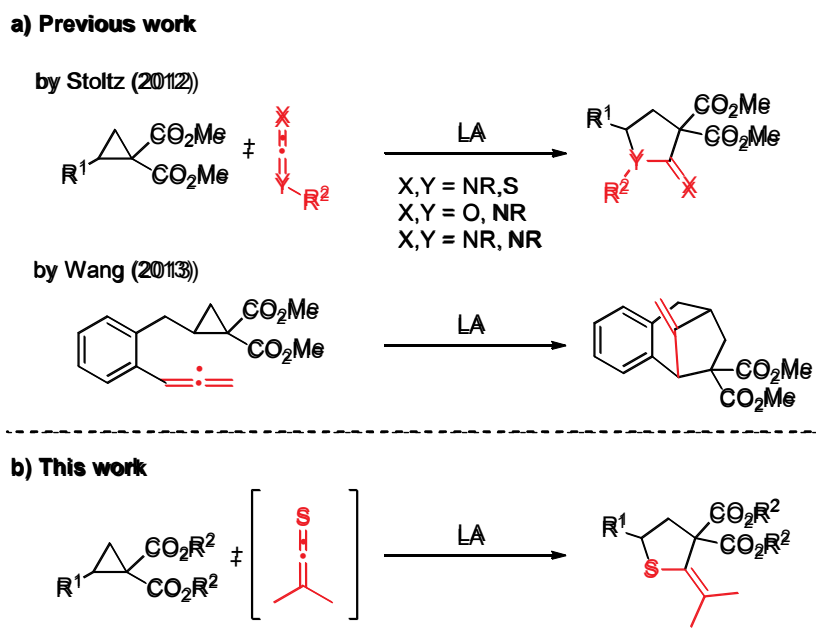

To start our investigations, we used D-A cyclopropane 1a and 3-thioxocyclobutanone $\mathbf{2 a}$ as model substrates. Initial reactions were carried out in dichloromethane at $60{ }^{\circ} \mathrm{C}$. Whereas $\mathrm{AlCl}_{3}$, $\mathrm{MgI}_{2}$ and $\mathrm{Zn}(\mathrm{OTf})_{2}$ as Lewis acid showed no conversion, product formation was observed with $\mathrm{Sn}(\mathrm{OTf})_{2}$ and $\mathrm{Yb}(\mathrm{OTf})_{3}$ in moderate yield (Table 1, entries 1-5). Subsequently, other common Lewis acids have been subjected to the reaction conditions, whereby $\mathrm{Sc}(\mathrm{OTf})_{3}$ seemed to be the most promising catalyst 
with an initial product formation of $95 \%$ yield (Table 1, entry 6). Changing the solvent to toluene resulted in a complex mixture, while THF showed no conversion of cyclopropane 1a (Table 1, entries 7-8). Using dichloroethane as solvent was invaluable and delivered the desired product 3aa in quantitative yield (Table 1, entry 9). As shown in entry 10, decreasing the reaction temperature to $40^{\circ} \mathrm{C}$ was detrimental to product formation.

Table 1. Optimization of the Reaction Conditions ${ }^{a}$

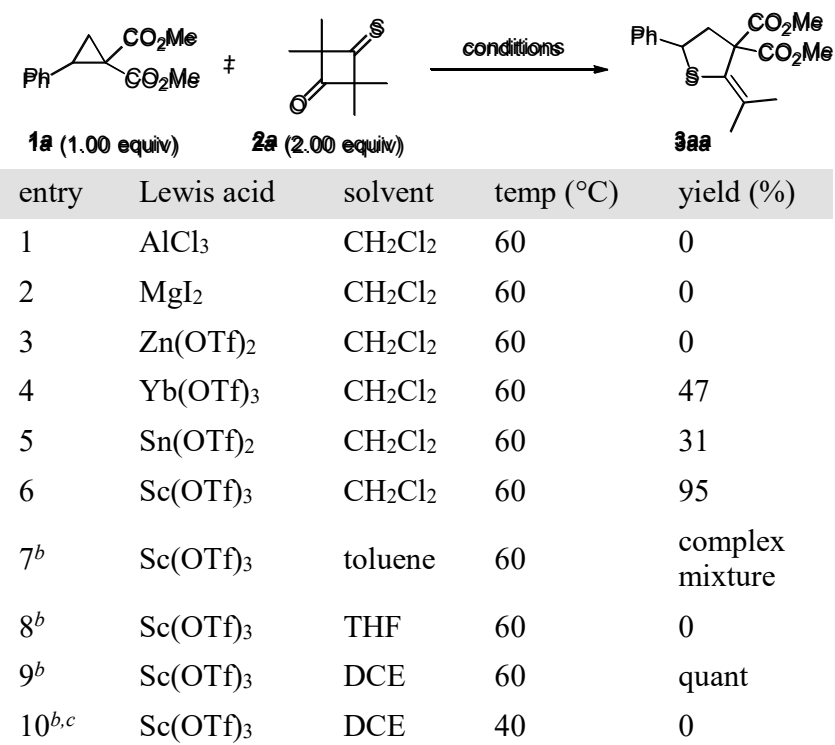

${ }^{a}$ Reaction conditions: 1a $(100 \mu \mathrm{mol}), \mathbf{2 a}(200 \mu \mathrm{mol})$, Lewis acid (10 mol \%), solvent $(2.5 \mathrm{~mL})$, under $\mathrm{Ar}, 16 \mathrm{~h}$, yields represent isolated and purified products, ${ }^{b} 12 \mathrm{~h}, \mathrm{DCE}=$ dichloroethane, ${ }^{c}$ only formation of intermediate 4 aa was observed

With the optimized conditions in hand we explored the generality of our protocol. Thus, we subjected various D-A cyclopropanes 1 to the standard procedure. As shown in Scheme 2, a broad variety of starting materials was tolerated. Phenyl substituents bearing halogens undergo the reaction with similar outcome (3ba-3ca), whereas methoxy or acetoxy attached to the phenyl donor show slightly less product formation (3da-3ea). Methyl substituents in ortho, meta and para position afforded 3fa-3ha in up to quantitative yield. Even trifluoromethyl-substituted aryl moieties (3ia) and other markedly electron-poor phenyl units (3ja-3ka) furnished the desired products in excellent yield. The transformation also proceeded smoothly with the highly electron-deficient perfluorophenyl donor in a respectable yield of $60 \%$ (3la). Increasing the $\pi$-system to a naphthyl residue generated the desired product 3 ma quantitatively, while decreasing the $\pi$-character to a vinyl donor leads to a less efficient transformation (3na). Decoration of the three-membered ring with annulated cyclohexyl (3oa) or thienyl (3pa) residues provided the desired products in moderate yield, while nitrogen donors gave products 3qa-3ra in up to $90 \%$ yield. Besides dimethyl ester acceptors, diethyl- and dibenzyl-substituted acceptors have been shown to undergo the reaction in good yields (3sa3ta).

We then investigated the outcome of the reaction on using different 3-thioxocyclobutanones. Those could be accessed from the corresponding acyl chlorides by a two-step procedure including ketene formation under basic conditions followed by dimerization in good yields. As shown in Scheme 3 five- and six-membered carbocycles were attached to the semicyclic double bond system. A slight decrease of the yield was observed with increasing ring size.

Scheme 2. Scope with Regard to Donor-Acceptor Cyclopropanes $^{a}$
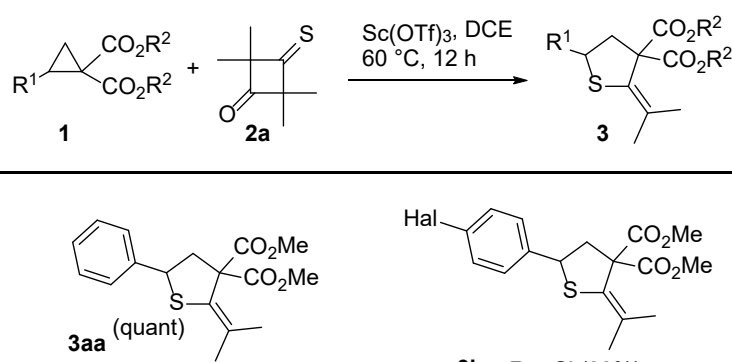

3ba, $\mathrm{R}=\mathrm{Cl}(99 \%)$ 3ca, $\mathrm{R}=\mathrm{Br}$ (quant)
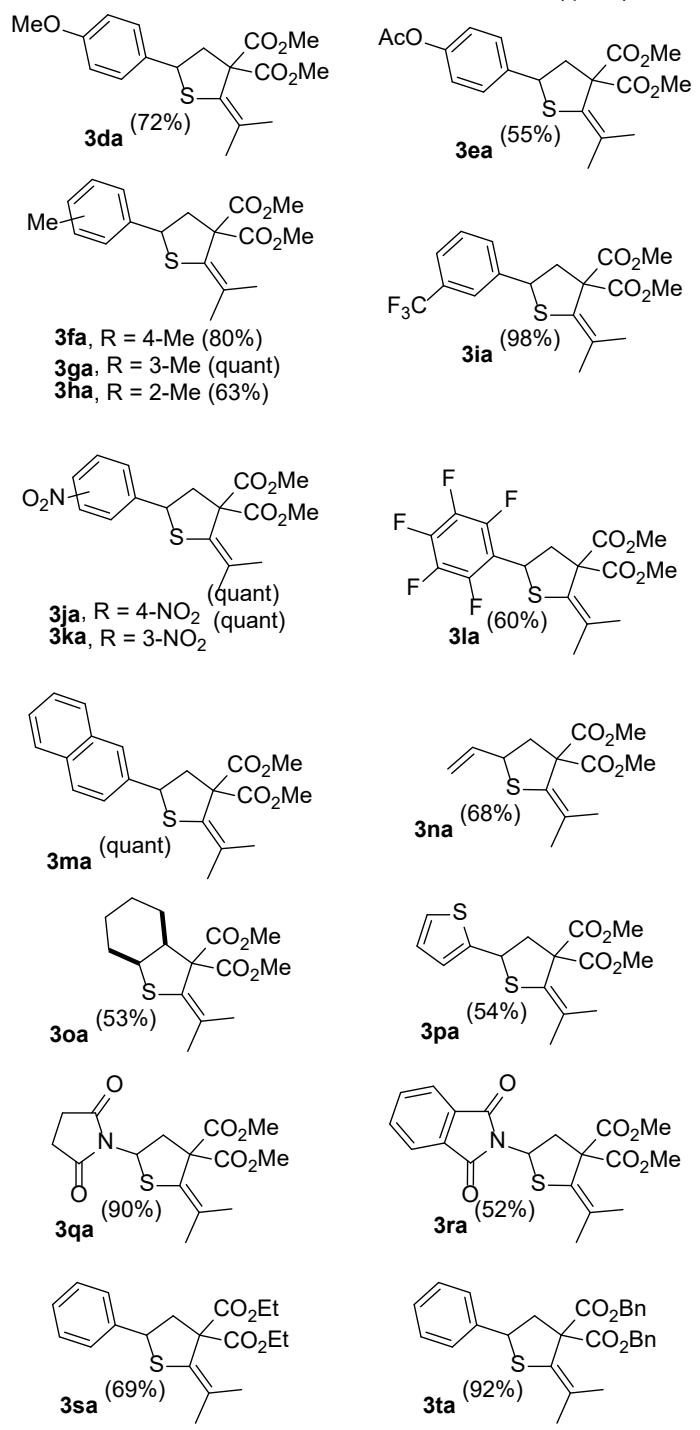

${ }^{a}$ Reaction conditions: $1(100 \mu \mathrm{mol}), \mathbf{2 a}(200 \mu \mathrm{mol}), \operatorname{Sc}(\mathrm{OTf})_{3}$ (10 mol \%), DCE $(2.5 \mathrm{~mL})$, under $\mathrm{Ar}, 60{ }^{\circ} \mathrm{C}, 12 \mathrm{~h}$; yields represent isolated and purified products; $\mathrm{DCE}=$ dichloroethane

Scheme 3. Scope with Regard to the 3-Thioxocyclobutanone Motif $^{a}$ 


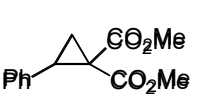

1 a

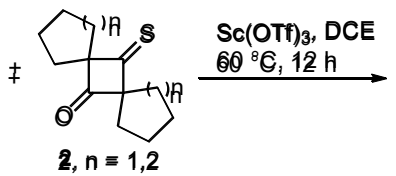

2. $⿻ \equiv 1,2$

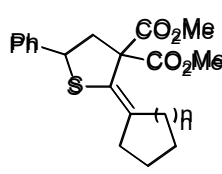
3ิณe, ค $\equiv 2(44 \% \%)$
3ิลม่า, ก $\equiv 1(54 \%)$

${ }^{a}$ Reaction conditions: 1a $(200 \mu \mathrm{mol}), 2(400 \mu \mathrm{mol}), \mathrm{Sc}(\mathrm{OTf})_{3}$ (10 mol \%), DCE (5.0 mL), under Ar, $60^{\circ} \mathrm{C}, 12 \mathrm{~h}$; yields represent isolated and purified products; $\mathrm{DCE}=$ dichloroethane

To get deeper insights into the reaction mechanism, we carried out several control experiments (Scheme 4). First, we were interested whether a ketone or a ketene moiety would also be able to insert. Therefore, we employed diketone 2a', which was subjected to the general reaction conditions. In this experiment, no conversion of cyclopropane 1a was observed. On using dithioketone 2a" a complex mixture resulted, but we were able to isolate crude 3 aa in $76 \%$ yield (Scheme 4 , eq 1). Next, we observed that spiro compound 4 aa was obtained in $59 \%$ yield if one uses $\mathrm{TiF}_{4}$ as Lewis acid (Scheme 4, eq 2). This observation strengthened our hypothesis that the thiocarbonyl inserts first, followed by the release of dimethylketene, and this assumption was proved by another experiment. Compound 4aa was subjected to the general reaction conditions; compound 3aa resulted in nearly quantitative yield (Scheme 4, eq 3 ). Interestingly, no conversion of 4aa was observed if the reaction was run without $\mathrm{Sc}(\mathrm{OTf})_{3}$ as Lewis acid. To prove the formation of dimethylketene the reaction was performed in presence of phenol as trapping reagent. GC-MS analysis showed indeed the desired trapping product (see Supporting Information).

\section{Scheme 4. Control Experiments}
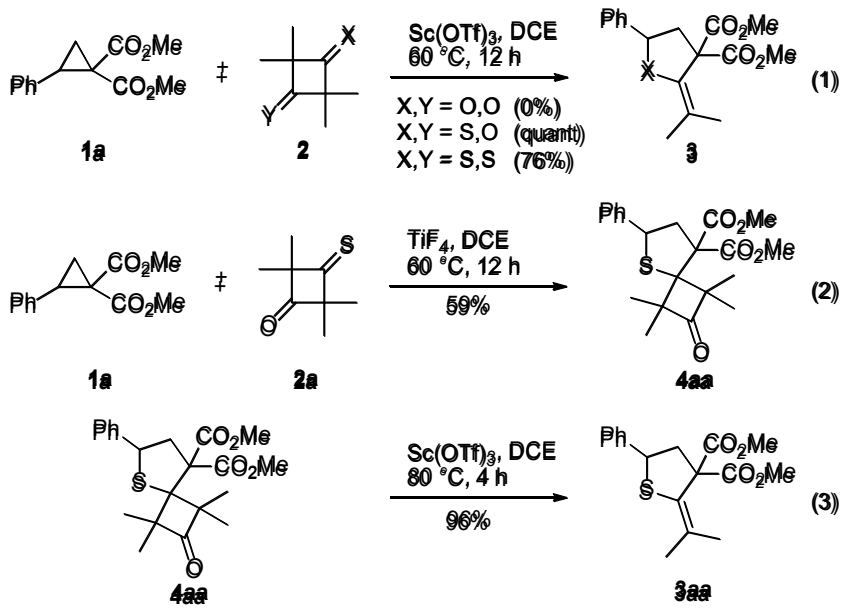

As corroborated by our control experiments, we propose the following reaction pathway (Scheme 5$)$. $\mathrm{Sc}(\mathrm{OTf})_{3}$ activates cyclopropane $(S)$-1a' by interacting with the geminal diester moiety to allow an $\mathrm{S}_{\mathrm{N}} 2$-type nucleophilic attack of the thioketone 2a, followed by a ring-closure to intermediate $(R)-\mathbf{4 a a}{ }^{12}$ Coordination of $\mathrm{Sc}(\mathrm{OTf})_{3}$ to the oxygen of the ketone paves the way for the terminating cleavage of dimethylketene, ${ }^{13}$ whereby product $(R)$-3aa' is released and $\mathrm{Sc}(\mathrm{OTf})_{3}$ is able to undergo the next catalytic cycle.
Scheme 5. Proposed Mechanism

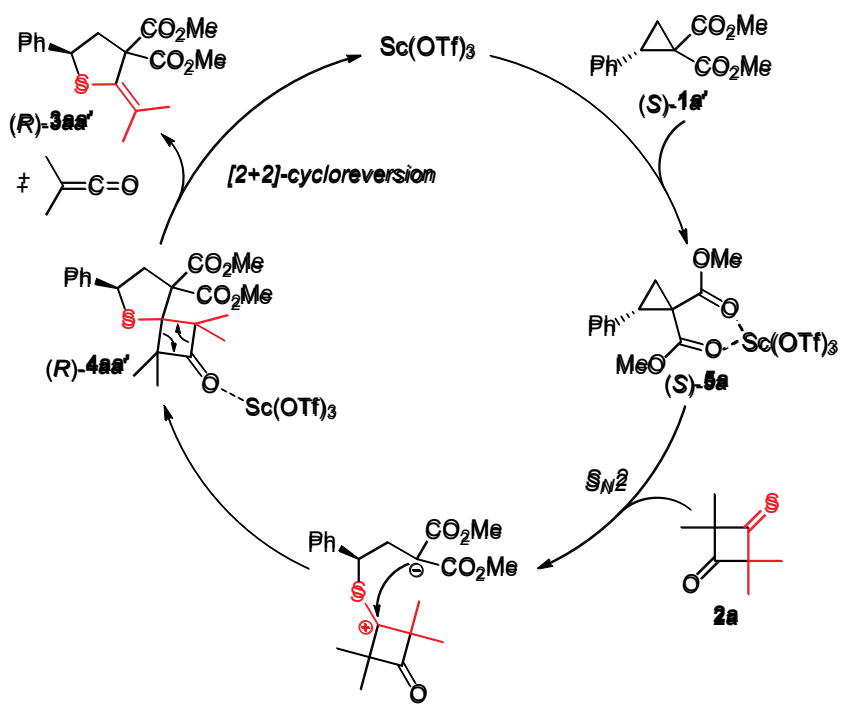

The utility of the formal thioketene insertion was demonstrated by selected further transformations (Scheme 6). Undecorated thioenol ether derivative 3aa was subjected to ozonolysis to furnish thiolactone 6 in $36 \%$ yield. Oxidation with equimolar amounts of $m$-CPBA delivered sulfoxide 7 (87\%), whereas full oxidation with an excess of $m$-CPBA resulted in nearly quantitative formation of sulfone 8. Krapcho decarboxylation with $\mathrm{KCN}$ in wet DMSO afforded monoester 9 in moderate yield and a diastereomeric ratio of 6:1 with the cis-isomer being favored. Treatment with DDQ initiated an elimination reaction to furnish dihydrothiophene $\mathbf{1 0}$ in $87 \%$ yield.

\section{Scheme 6. Follow-Up Chemistry}

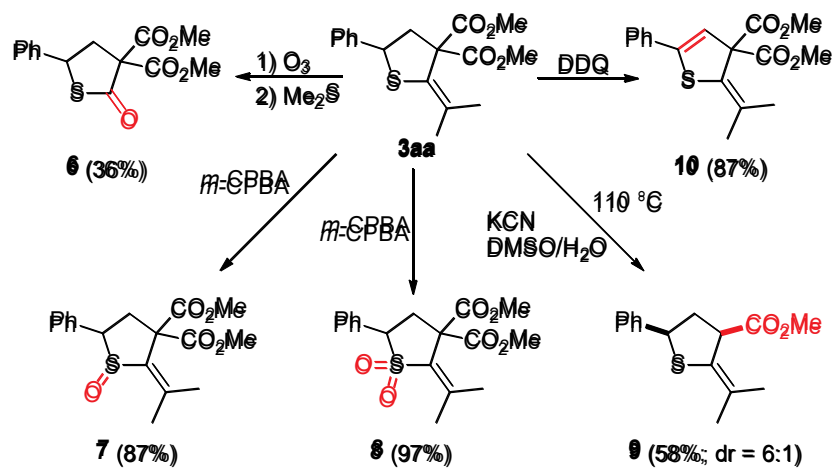

In summary, we have developed a new process for the formal insertion of thioketenes into D-A cyclopropanes under Lewis acid catalysis. 3-Thioxocyclobutanone derivatives were successfully utilized as thioketene surrogates and led to a broad scope of sulfur-containing heterocycles with a semicyclic thioether moiety. Furthermore, additional experiments gave hints of a mechanism that follows a formal [3+2]-cycloaddition and a subsequent [2+2]-cycloreversion releasing dialkyl ketene.

\section{ASSOCIATED CONTENT}

\section{Supporting Information}


The Supporting Information is available free of charge on the ACS Publications website.

Detailed experimental procedures, analytical data for all new compounds (PDF), crystal data for 3aa (CIF).

\section{AUTHOR INFORMATION}

\section{Corresponding Author}

E-mail: d.werz@tu-braunschweig.de

ORCID

André U. Augustin: 0000-0002-6425-2843

Daniel B. Werz: 0000-0002-3973-2212

\section{Notes}

The authors declare no competing financial interest.

\section{ACKNOWLEDGMENT}

This research was supported by the European Research Council (ERC Consolidator Grant "GAINBYSTRAIN" to D.B.W.).

\section{REFERENCES}

(1) (a) Wenkert, E.; Alonso, M. E.; Buckwalter, B. L.; Chou, K. J. J. Am. Chem. Soc. 1977, 99, 4778. (b) Reissig, H.-U.; Hirsch, E. Angew. Chem., Int. Ed. Engl. 1980, 19, 813. (c) Brückner, C.; Reissig, H.U. Angew. Chem., Int. Ed. Engl. 1985, 24, 588.

(2) For reviews on D-A cyclopropanes: (a) Reissig, H.-U.; Zimmer, R. Chem. Rev. 2003, 103, 1151. (b) Yu, M.; Pagenkopf, B. L. Tetrahedron 2005, 61, 321. (c) Agrawal, D.; Yadav, V. K. Chem. Commun. 2008, 6471. (d) Carson, C. A.; Kerr, M. A. Chem. Soc. Rev. 2009, 38, 3051. (e) De Simone, F.; Waser, J. Synthesis 2009, 3353. (f) Cavitt, M. A.; Phun, L. H.; France, S. Chem. Soc. Rev. 2014, 43, 804. (g) Schneider, T. F.; Kaschel, J.; Werz, D. B. Angew. Chem. Int. Ed. 2014, 53, 5504. (h) Novikov, R. A.; Tomilov, Y. V. Mendeleev Commun. 2015, 25, 1. (i) O’Connor, N. R.; Wood, J. L.; Stoltz, B. M. Isr. J. Chem. 2016, 56,431

(3) Gordon, M. S. J. Am. Chem. Soc. 1980, 102, 7419

(4) Selected examples: (a) Parsons, A. T.; Johnson, J. S. J. Am. Chem. Soc. 2009, 131, 3122. (b) Xing, S.; Pan, W.; Liu, C.; Ren, J.; Wang, Z. Angew. Chem. Int. Ed. 2010, 49, 3215. (c) Xing, S.; Li, Y.; Li, Z.; Liu, C.; Ren, J.; Wang, Z. Angew. Chem. Int. Ed. 2011, 50, 12605. (d) Qu, J.-P.; Liang, Y.; Xu, H.; Sun, X.-L.; Yu, Z.-X.; Tang, Y. Chem. Eur. J. 2012, 18, 2196. (e) Wang, H.; Yang, W.; Liu, H.; Wang, W.; Li, H. Org. Biomol. Chem. 2012, 10, 5032. (f) Benfatti, F.; de Nanteuil, F.; Waser, J. Org. Lett. 2012, 14, 386. (g) Zhu, W.; Fang, J.; Liu, Y.; Ren, J.; Wang, Z. Angew. Chem. Int. Ed. 2013, 52, 2032. (h) Xu, H.; Qu, J.-P.; Liao, S.; Xiong, H.; Tang, Y. Angew. Chem. Int. Ed. 2013, 52, 4004. (i) Chakrabarty, S.; Chatterjee, I.; Wibbeling, B.; Daniliuc, C. G.; Studer, A. Angew. Chem. Int. Ed. 2014, 53, 5964. (j) Gladow, D.; Reissig, H.-U. J. Org. Chem. 2014, 79, 4492. (k) Ren, J.; Bao, J.; Ma, W.; Wang, Z. Synlett 2014, 25, 2260. (1) Tombe, R.; Iwamoto, T.; Kurahashi, T.; Matsubara, S. Synlett 2014, 25, 2281. (m) Xu, H.; Hu, J.-L.; Wang, L.; Liao, S.; Tang, Y. J. Am. Chem. Soc. 2015, 137, 8006. (n) Wang, S.-W.; Guo, W.-S.; Wen, L.-R.; Li, M. RSC Adv. 2015, 5, 47418. (o) Garve, L. K. B.; Petzold, M.; Jones, P. G.; Werz, D. B. Org. Lett. 2016, 18, 564. (p) Gosh, A.; Mandal, S.; Chattaraj, P. K.; Banerjee, P. Org. Lett. 2016, 18, 4940. (q) Garve, L. K. B.; Pawliczek, M.; Wallbaum, J.; Jones, P. G.; Werz, D. B. Chem. Eur. J. 2016,
22, 521. (r) Sabbatani, J.; Maulide, N. Angew. Chem. Int. Ed. 2016, 55 6780. (s) Borisov, D. D.; Novikov, R. A.; Tomilov, Y. V. Angew. Chem. Int. Ed. 2016, 55, 12233. (t) Wang, Z.-H.; Zhang, H.-H.; Wang, D.-M.; Xu, P.-F.; Luo, Y.-C. Chem. Commun. 2017, 53, 8521. (u) Garve, L. K. B.; Kreft, A.; Jones, P. G.; Werz, D. B. J. Org. Chem. 2017, 82, 9235. (v) Preindl, J.; Chakrabarty, S.; Waser, J. Chem. Sci. 2017, 8, 7112 .

(5) Selected examples: (a) Brand, C.; Rauch, G.; Zanoni, M.; Dittrich, B.; Werz, D. B. J. Org. Chem. 2009, 74, 8779. (b) Schneider, T. F.; Kaschel, J.; Dittrich, B.; Werz, D. B. Org. Lett. 2009, 11, 2317. (c) Gharpure, S. J.; Shukla, M. K.; Vijayasree, U. Org. Lett. 2009, 11, 5466. (d) Schneider, T. F.; Kaschel, J.; Awan, S. I.; Dittrich, B.; Werz, D. B. Chem. Eur. J. 2010, 16, 11276. (e) Schneider, T. F.; Werz, D. B. Org. Lett. 2011, 13, 1848. (f) Kaschel, J.; Schneider, T. F.; Kratzert, D.; Stalke, D.; Werz, D. B. Angew. Chem. Int. Ed. 2012, 51, 11153. (g) Wang, P.; Song, S.; Miao, Z.; Yang, G.; Zhang, A. Org. Lett. 2013, 15, 3852. (h) Grover, H. K.; Emmett, M. R.; Kerr, M. A. Org. Lett. 2013, 15, 4838. (i) Schmidt, C. D.; Kaschel, J.; Schneider, T. F.; Kratzert, D. Stalke, D.; Werz, D. B. Org. Lett. 2013, 15, 6098. (j) Kaschel, J.; Schmidt, C. D.; Mumby, M.; Kratzert, D.; Stalke, D.; Werz, D. B. Chem. Comm. 2013, 49, 4403 .

(6) Selected examples: (a) Garve, L. K. B.; Barkawitz, P.; Jones, P. G.; Werz, D. B. Org. Lett. 2014, 16, 5804. (b) Ivanov, K. L.; Villemson, E. V.; Budynina, E. M.; Ivanova, O. A.; Trushkov, I. V.; Melnikov, M. Y. Chem. Eur. J. 2015, 21, 4975. (c) Xia, Y.; Liu, X.; Zheng, H.; Lin, L.; Feng, X. Angew. Chem. Int. Ed. 2015, 54, 227. (d) Xia, Y.; Lin, L.; Chang, F.; Liao, Y.; Liu, X.; Feng, X. Angew. Chem. Int. Ed. 2016 55, 12228. (e) Das, S.; Daniliuc, C. G.; Studer, A. Org. Lett. 2016, 18 , 5576. (f) Kaicharla, T.; Roy, T.; Thangaraj, M.; Gonnade, R. G.; Biju, A. T. Angew. Chem. Int. Ed. 2016, 55, 10061. (g) Pitts, C. R.; Ling, B.; Snyder, J. A.; Bragg, A. E.; Lectka, T. J. Am. Chem. Soc. 2016, 138, 6598. (h) Wallbaum, J.; Garve, L. K. B.; Jones, P. G.; Werz, D. B Chem. Eur. J. 2016, 22, 18756. (i) Wallbaum, J.; Garve, L. K. B.; Jones, P. G.; Werz, D. B. Org. Lett. 2017, 19, 98. (j) Garve, L. K. B.; Jones, P. G.; Werz, D. B. Angew. Chem. Int. Ed. 2017, 56, 9226. (k) Das, S.; Daniliuc, C. G.; Studer, A. Angew. Chem. Int. Ed. 2017, 56, 11554. (l) Lücht, A.; Patalag, L. J.; Augustin, A. U.; Jones, P. G.; Werz, D. B. Angew. Chem. Int. Ed. 2017, 56, 10587.

(7) Goldberg, A. F. G.; O'Connor, N. R.; Craig II, R. A.; Stoltz, B. M. Org. Lett. 2012, 14, 5314.

(8) Feng, M.; Yang, P.; Yang, G.; Chen, W.; Chai, Z. J. Org. Chem. 2017, 83, 174.

(9) Wang, Z.; Ren, J.; Wang, Z. Org. Lett. 2013, 15, 5682.

(10) (a) Raasch, M. S. J. Org. Chem. 1970, 35, 3470. (b) Schaumann, E. Chem. Ber. 1982, 115, 2755. (c) Schaumann, E. Tetrahedron 1988, 44, 1827. (d) Mlostoń, G.; Gendek, T.; Heimgartner, H. Helv. Chim. Acta 1998, 81, 1585.

(11) Augustin, A. U.; Sensse, M.; Jones, P. G.; Werz, D. B. Angew. Chem. Int. Ed. 2017, 56, 14293.

(12) Unfortunately, a complete baseline separation of (rac)-3aa by chiral HPLC was unsuccessful. Therefore, $(R)$-3aa' was transformed to sulfone $(R)-\mathbf{8}$ ' and enantiomeric excess could then be determined by chiral HPLC to give $93 \%$ ee from cyclopropane $(S)-1$ ' $(95 \%$ ee).

(13) Similar observations have been made by the formation of cycloadducts with aziridine derivatives: Mlostoń, G.; Urbaniak, K.; Linden, A.; Heimgartner, H. Helv. Chim. Acta 2002, 85, 2644.

(14) The CIF files have been deposited with the Cambridge Crystallographic Data Centre as supplementary publication no. CCDC1812319 (3aa). These data can be obtained free of charge from The Cambridge Crystallographic Data Centre. 